\title{
Estimasi Beban Cemar dan Laju Dekomposisi Bahan Organik di Waduk Ir. H. Djuanda, Jawa Barat
}

\author{
Decomposition Rate and Organic Matter Load at Ir. H. Djuanda \\ Reservoir, West Java
}

\author{
ANDRI WARSA, LISMINING PUJIYANI ASTUTI \\ Balai Riset Pemulihan Sumber daya Ikan \\ Jalan Cilalawi No 1 Jatiluhur, Purwakarta, Jawa Barat 41152 \\ Email: andriwarsa@yahoo.co.id
}

\begin{abstract}
Ir. H. Djuanda or Jatiluhur reservoir as a multifunction water body with one of utilization as fish cultivation activity. Uneaten feed and fish excretion were organic matter sources. The number of floating net cages was increasing and it caused increasing in organic matter load. The objective of the research was to known organic matter load and decomposition rate $(k)$ and BOD (Biochemical oxygen demand) ultimate (Lo) at Jatiluhur Reservoir. The research was done in February and August 2018 at three locations were Astap, Pasir Canar and Pulau Aki. The result of the research shown was organic load from cultivation activity was 70,595 tons/year. The decomposition rate of organic matter around 0.10-0.25 per day with $B O D$ ultimate around $6.80-8.11 \mathrm{mg} / \mathrm{L}$. The value of Lo was affected by organic matter concentration.
\end{abstract}

Keywords: Ir. H. Djuanda Reservoir, organic matter, decomposition rate, BOD ultimate

\begin{abstract}
ABSTRAK
Waduk Ir. H. Djuanda atau yang dikenal dengan Waduk Jatiluhur merupakan waduk multifungsi yang salah satu pemanfaatannya untuk kegiatan budidaya ikan. Sisa pakan yang terbuang dan ekresi ikan merupakan sumber masukkan bahan organik. Jumlah keramba jaring apung (KJA) yang semakin bertambah akan menyebabkan beban masukkan bahan organik meningkat. Tujuan penelitian ini adalah untuk mengetahui beban masukkan bahan organik dari kegiatan budidaya dan laju dekomposisi bahan organik (k) serta BOD (Biochemical oxygen demand) ultimate $\left(L_{0}\right)$ di Waduk Jatiluhur. Penelitian dilakukan pada bulan Februari dan Agustus 2018 pada tiga lokasi yaitu Astap, Pasir Canar dan Pulau Aki. Pendekatan yang digunakan dalam penentuan nilai k dan Lo adalah metode Grafik Thomas. Hasil penelitian menunjukkan bahwa beban masukkan bahan organik dari kegiatan budidaya sebesar 70.595 ton/tahun. Beban masukkan bahan organik telah melebihi daya dukung perairan. Nilai $k$ untuk dekomposisi bahan organik di Waduk Jatiluhur berkisar 0,10-0,25 per hari dengan nilai Lo berkisar 6,80$8,11 \mathrm{mg} / \mathrm{L}$. Nilai Lo dipengaruhi oleh konsentrasi bahan organik di perairan.
\end{abstract}

Kata kunci: Waduk Ir. H. Djuanda, bahan organik, laju peluruhan, BOD ultimate

\section{PENDAHULUAN}

\subsection{Latar belakang}

Biochemical oxygen demand (BOD) merupakan parameter yang digunakan dalam menentukan kualitas air selain nutrien dan padat total terlarut ${ }^{(1,2)}$. Nilai BOD akan menggambarkan tingkat pencemaran suatu perairan yang disebabkan oleh masukkan bahan organik(3). Parameter BOD menggambarkan fraksi bahan organik yang dapat terdekomposisi oleh bakteri pada kondisi aerob $^{(4,5)}$. Dekomposisi bahan organik di perairan menggunakan oksigen terlarut sehingga menyebabkan penurunan konsentrasi oksigen terlarut ${ }^{(6)}$. Pengukuran nilai BOD pada interval waktu tertentu dapat digunakan untuk mengetahui laju peluruhan bahan organik dan BOD ultimate ${ }^{(7)}$. Nilai BOD dapat dijadikan indikator tingkat pencemaran pada suatu badan air(8).

Waduk Ir. H. Djuanda atau yang dikenal dengan Waduk Jatiluhur memiliki luas 8.300 ha. Waduk ini merupakan waduk multifungsi yang dimanfaatkan untuk kegiatan budidaya ikan di dalam keramba jaring apung (KJA). Aktivitas budidaya dapat memberikan beban masukkan bahan organik dan nutrien yang berasal dari pakan dan sisa metabolisme ikan ${ }^{(9,10)}$. Bahan organik yang berasal dari sisa pakan yang terbuang tersebut akan mengendap di dasar perairan sedangkan ekresi ikan akan terdispersi ke perairan ${ }^{(11)}$. Beban masukkan bahan organik diperairan akan menyebabkan kenaikan nilai BOD serta peningkatan status trofik perairan 
yang ditandai tingginya konsentrasi nutrien $\mathrm{N}$ dan $\mathrm{P}^{(12)}$. Penelitian mengenai peluruhan dan beban cermar bahan organik di Waduk Jatiluhur belum banyak dilakukan. Hasil penelusuran pustaka menunjukkan hanya dua kegiatan penelitian yang mengkaji kedua aspek tersebut ${ }^{(13,14)}$. Pengambilan contoh air pada penelitian Astuti et al. ${ }^{(13)}$ hanya dilakukan pada satu lokasi yaitu zona budidaya sedangkan penelitian Simarmata et al. ${ }^{(14)}$ hanya melakukan analisis data dengan satu metode pendekatan. Pada penelitian ini, contoh air diambil pada beberapa lokasi dan waktu yang diharapkan dapat menggambarkan laju peluruhan bahan organik di Waduk Jatiluhur. Penelitian ini perlu dilakukan karena nilai BOD dapat menggambarkan kondisi kualitas air pada suatu perarain ${ }^{(15)}$. Keberadaan bahan organik diperairan berkaitan dengan ketersediaan oksigen terlarut pada suatu badan air karena oksigen terlarut diperlukan untuk mendekomposisi bahan organik tersebut ${ }^{(16)}$.

\subsection{Tujuan Penelitian}

Tujuan dari penelitian ini adalah untuk menghitung besaran beban masukkan bahan organik dari kegiatan budidaya dan laju dekomposisi (k) serta BOD ultimate $\left(L_{0}\right)$ di Waduk Ir. H. Djuanda, Jawa Barat.

\section{BAHAN DAN METODE}

\subsection{Waktu dan Lokasi Penelitian}

Penelitian dilakukan di Waduk Jatiluhur pada bulan Februari dan Agustus 2018. Periode Pengambilan contoh air tersebut berdasarkan pada musim hujan (Februari) dan kemarau (Agustus). Berdasarkan data curah hujan yang diperoleh dari Perum Jasa Tirta (PJT II) menunjukkan bahwa curah hujan rata-rata pada bulan Februari dan Agustus masing-masing adalah 206,5 dan 1,8 $\mathrm{mm} /$ hari. Pengambilan contoh air dilakukan di tiga lokasi yaitu Astap, Pasir Canar dan Pulau Aki (Gambar 1). Contoh air diambil dengan menggunakan Kemmerer water sampler dan dimasukkan kedalam botol polietilen 3,0 L. Contoh air kemudian dimasukkan ke dalam cool box yang telah diberi es. Parameter lingkungan pendukung juga diamati pada lokasi dan waktu yang sama dengan pengambilan contoh air (Tabel 1).

Tabel 1. Parameter kualitas air yang diamati

\begin{tabular}{|c|c|c|}
\hline Parameter & satuan & Metode/alat \\
\hline $\begin{array}{l}\text { Suhu } \\
\mathrm{pH}\end{array}$ & ${ }^{\circ} \mathrm{C}$ & $\begin{array}{l}\text { YSI Professoinal } \\
\text { YSI Professoinal }\end{array}$ \\
\hline $\begin{array}{l}\text { Oksigen } \\
\text { terlarut }\end{array}$ & $\mathrm{mg} / \mathrm{L}$ & Titrasi Winkler ${ }^{(17)}$ \\
\hline $\begin{array}{l}\text { Bahan } \\
\text { organik }\end{array}$ & $\mathrm{mg} / \mathrm{L}$ & $\begin{array}{l}\text { Titrasi Kalium Permanganat } \\
\qquad\left(\mathrm{KMnO}_{4}\right)^{(17)}\end{array}$ \\
\hline
\end{tabular}

Pengamatan laju peluruhan dilakukan bahan organik dilakukan di Laboratorium Balai Riset Pemulihan Sumberdaya ikan. Contoh air diaerasi dengan bantuan aerator ${ }^{(18)}$ selama 3 jam dan kemudian dibagi ke dalam tujuh botol winkler 125 $\mathrm{ml}$. Pengamatan oksigen terlarut dilakukan pada interval 2 hari dengan menggunakan metode titrasi winkler. Selama inkubasi botol dibungkus dengan plastik polybag hitam dan dimasukkan di dalam coolbox. Suhu selama inkubasi adalah $26,5 \pm 0,5^{\circ} \mathrm{C}$. Inkubasi contoh air pada periode waktu tertentu dapat digunakan untuk menentukan nilai BOD ultimate $\left(L_{\circ}\right)$ dan laju degradasi $(k)$ bahan organik(19).

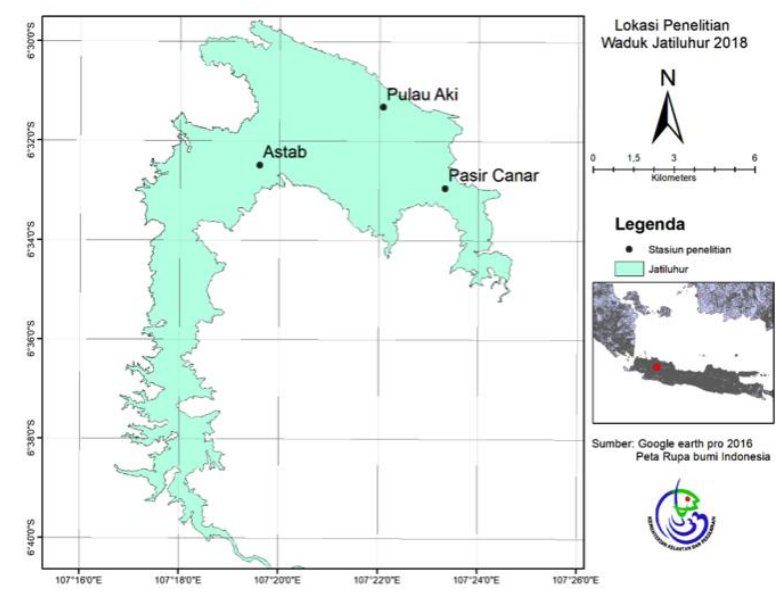

Gambar 1. Lokasi pengambilan contoh air di Waduk Jatiluhur

Jumlah Keramba jaring apung (KJA) yang beroperasi di Waduk Jatiluhur diperoleh dari penelusuran pustaka dan perhitungan berdasarkan peta citra google earth sampai dengan tahun 2016. Penggunaan citra tahun 2016 dapat menggambarkan jumlah KJA yang beroperasi karena sejak tahun 2014 Dinas Peternakan dan Perikanan, Purwakarta sudah tidak memberikan izin bagi usaha KJA baru sehingga tidak terdapat penambahan jumlah KJA yang beroperasi. Hasil perhitungan citra 2015 juga menunjukkan bahwa jumlah KJA yang beroperasi sama dengan jumlah KJA berdasarkan citra 2016. Program nasional Citarum harum mampu mengurangi jumlah KJA pada tahun 2017-2018 sebanyak 6.855 petak hingga akhir 2018 sehingga jumlah diperkirakan KJA yang beroperasi sebanyak 42.169 petak. Untuk produksi ikan untuk setiap petak KJA diperoleh dari Dinas Peternakan dan Perikanan, Kabupaten Purwakarta dan Wawancara dengan 15 petani ikan. Responden dipilih secara sengaja berdasarkan azas keterwakilan zona budiaya ${ }^{(20)}$. Wawancara dengan petani juga dilakukan untuk mengetahui nilai rasio konversi pakan ikan. Data tersebut akan digunakan untuk menghitung 
beban cemar bahan organik yang masuk perairan Waduk Jatiluhur.

\subsection{Analisis data}

\subsubsection{Beban cemar bahan organik dari budidaya}

Beban cemar bahan organik dari aktivitas budidaya dihitung berdasarkan jumlah pakan yang diberikan serta produksi ikan budidaya ${ }^{(21)}$ yang dihitung berdasarkan pendekatan dari(22) dengan persamaan sebagai berikut:

$$
\begin{array}{lll}
\mathrm{LBO}_{\mathrm{BO}}= & \mathrm{JP}_{\mathrm{k}}-\mathrm{Pl}_{\mathrm{k}} & \ldots \ldots \ldots \ldots \ldots \ldots(1) \\
\text { Keterangan: } & \\
\mathrm{L}_{\mathrm{BO}}= & \text { Beban bahan organik (ton/tahun) } \\
\mathrm{JP}_{\mathrm{k}}= & \text { Jumlah pakan total (ton/tahun berat kering) } \\
\mathrm{Pl}_{\mathrm{k}}= & \text { Produksi ikan total (ton/tahun berat kering) }
\end{array}
$$

Asumsi yang digunakan adalah berat kering ikan adalah $25 \%$ dari berat basah seangkan berat kering dari pakan adalah $50 \%$ dari berat pakan yang diberikan ${ }^{(23)}$.

\subsubsection{Konsentrasi oksigen terlarut jenuh}

Oksigen jenuh (DOs) jenuh diperarian dihitung dengan menggunakan pendekatan dari(24) berdasarkan parameter suhu air dengan persamaan sebagai berikut:

$$
\begin{aligned}
& \text { Dos }=0,0035 T^{2}-0,3369 T+14,407 \\
& \text { Keterangan: } \\
& \mathrm{T}=\text { suhu air }\left({ }^{\circ} \mathrm{C}\right)
\end{aligned}
$$

\subsubsection{BOD ultimate dan Laju dekomposis bahan organik}

Penentuan BOD ultimate $\left(L_{0}\right)$ dan laju peluruhan (k) bahan organik dihitung dengan tiga pendekatan yaitu metode Least Square (LS), Graphical Thomas (GT) dan Daily Difference $(\mathrm{DD})^{(25,26,27)}$. Laju dekomposisi bahan organik diasumsikan mengikuti persamaan reaksi orde satu(28). Nilai BOD pada waktu $t$ berdasarkan waktu dapat dituliskan dengan persamaan:

$y t=L_{o}\left(1-e^{-k t}\right)$

keterangan:

$$
\begin{array}{lll}
y_{t} & = & \text { BOD teoritis pada waktu } \mathrm{t}(\mathrm{mg} / \mathrm{L}) \\
\mathrm{L}_{\mathrm{o}} & = & \mathrm{BOD} \text { ultimate }(\mathrm{mg} / \mathrm{L}) \\
\mathrm{k} & = & \text { Laju peluruhan bahan organik (per hari) }
\end{array}
$$

Nilai $L_{\circ}$ dan $k$ dari ketiga metode akan digunakan untuk menghitung nilai BOD teoritis berdasarkan waktu. Nilai $L_{o}$ dan $k$ yang memberikan selisih nilai mutlak (D) terkecil antara nilai BOD hasil analisis laboratorium dan BOD teori hasil perhitungan akan ditetapkan sebagai nilai $L_{o}$ dan $\mathrm{k}^{(26)}$. Nilai $\mathrm{D}$ dihitung dengan persamaan sebagai berikut:

$$
\begin{aligned}
& \text { D } \sum_{i=1}^{k}\left(0_{0} \quad E_{i}\right) / E_{:} \\
& \text {Keterangan: } \\
& \mathrm{O}_{\mathrm{i}}=\text { BOD hasil pengamatan }(\mathrm{mg} / \mathrm{L}) \\
& \mathrm{E}_{\mathrm{i}}=\mathrm{BOD} \text { teoritis hasil perhitungan }(\mathrm{mg} / \mathrm{L})
\end{aligned}
$$

Simulasi dekomposisi bahan organik berdasarkan pendekatan ${ }^{(29)}$ dengan persamaan sebagai berikut:

$$
\begin{array}{llll}
\mathrm{C}_{\text {dek }}= & \mathrm{C}_{0}\left(1-\mathrm{e}^{-\mathrm{kt}}\right) & \ldots \ldots \ldots \ldots \ldots & (5) \\
\text { Keterangan: } & & \\
\mathrm{C}_{\text {dek }}= & \begin{array}{l}
\text { konsentrai Bahan } \\
\text { terdekomposisi }(\mathrm{mg} / \mathrm{L})
\end{array} \\
\mathrm{C}_{0}= & \text { konsentrasi bahan organik awal (mg/L) } \\
\mathrm{k} & = & \text { laju dekomposisi bahan organik (per hari) } \\
\mathrm{t} & = & \text { Waktu (hari) }
\end{array}
$$

Akumulasi bahan organik di perairan dengan persamaan dihitung dengan persamaan sebagai berikut:

$$
\begin{aligned}
& =\sum_{t}^{A c_{b o}} L_{B O}-\left(L_{B O}\right. \\
& \text { *C) } \\
& \text { Keterangan: } \\
& A c_{b o}=\text { Akumulasi bahan organik } \\
& \text { C }=\text { Koefisien dekomposisi bahan }
\end{aligned}
$$

\section{HASIL DAN PEMBAHASAN}

\subsection{Baban masukkan bahan organik}

Hasil pengukuran parameter kualitas air pada lokasi penelitian menunjukkan bahwa Bahan organik di lokasi Pasir Canar lebih tinggi jika dibandingkan dengan lokasi lainnya (Tabel 2). $\mathrm{pH}$ perairan di ketiga lokasi cenderung sama yaitu pada bulan Agustus yaitu 6,5 sedangkan pada Bulan Februari pH di Pasir Canar cenderung lebih rendah yaitu 6,5 (asam). Suhu air berkisar berkisar $26,0-28,3^{\circ} \mathrm{C}$ dimana suhu tertinggi pada bulan Februari terdapat di lokasi pasir Canar sedangkan pada bulan Agustus terdapat dilokasi Astap.

Konsentrasi oksigen terlarut di lokasi penelitian sangat rendah yaitu $0,0-0,15 \mathrm{mg} / \mathrm{L}$ sedangkan hasil perhitungan untuk oksigen terlarut jenuh berkisar 7,70-8,01 $\mathrm{mg} / \mathrm{L}$. Konsentrasi oksigen terlarut yang jauh lebih rendah jika dibandingkan dengan konsentrasi oksigen terlarut jenuh menunjukkan penggunaannya untuk dekomposisi bahan organik.

Jumlah KJA yang beroperasi di Waduk Jatiluhur semakin bertambah setiap tahun pada 
tahun 2016 sebanyak 49.023 petak dari 2194 petak pada tahun 1998. Produktivitas untuk setiap petak telah mengalami penurunan dari 3,6 menjadi 2,4 ton/petak/tahun. Produksi total ikan budidaya ikan semakin bertambah karena meningkatnya jumlah KJA yang beroperasi. Hal ini berdampak pada semakin tingginya beban masukkan bahan organik keperairan (Tabel 3).

Tabel 2. Parameter kualitas air di Waduk Jatiluhur

\begin{tabular}{cccc}
\hline Parameter & \multicolumn{3}{c}{ Lokasi } \\
\cline { 2 - 4 } & Astap & Pulau Aki & Pasir Canar \\
\hline Suhu air $\left({ }^{\circ} \mathrm{C}\right)$ & 26,0 & Februari \\
pH & 7,0 & 7,4 & 27,2 \\
Oksigen terlarut (DO) $(\mathrm{mg} / \mathrm{L}$ & 0,15 & 0,15 & 7,0 \\
DO jenuh $(\mathrm{mg} / \mathrm{L})$ & 8,01 & 7,95 & 0,0 \\
Bahan organik $(\mathrm{mg} / \mathrm{L})$ & 7,58 & 6,95 & 7,83 \\
& & Agustus \\
Suhu air $\left({ }^{\circ} \mathrm{C}\right)$ & 27,1 & 28,3 & 27,3 \\
pH & 6,5 & 6,5 & 6,5 \\
Oksigen terlarut, (DO) $(\mathrm{mg} / \mathrm{L}$ & 0,0 & 0,0 & 0,0 \\
DO jenuh (mg/L) & 7,70 & 7,82 & 7,82 \\
Bahan organik (mg/L) & 16,11 & 13,63 & 17,97 \\
\hline Sumber
\end{tabular}

Sumber: data primer penelitian 2018

Tabel 3. Estimasi beban masukkan bahan organik di Waduk Jatiluhur

\begin{tabular}{|c|c|c|c|c|c|c|}
\hline \multirow[t]{2}{*}{ Tahun } & \multirow[t]{2}{*}{ petak } & \multicolumn{2}{|c|}{ Ikan (Ton) } & \multicolumn{2}{|c|}{ Pakan (ton) } & \multirow{2}{*}{$\begin{array}{c}\text { Estimasi } \\
\text { Beban (ton) }\end{array}$} \\
\hline & & Berat basah & Berat kering & Berat basah & Berat kering & \\
\hline $1998^{a}$ & 2.194 & 2.180 & 545 & 3.270 & 1.635 & 1.090 \\
\hline $2000^{a}$ & 2.537 & 3.791 & 948 & 5.687 & 2.843 & 1.896 \\
\hline $2001^{a}$ & 2.642 & 3.223 & 806 & 4.835 & 2.417 & 1.612 \\
\hline $2002^{a}$ & 2.628 & 4.917 & 1.229 & 7.376 & 3.688 & 2.459 \\
\hline $2003^{b}$ & 2.882 & 6.080 & 1.520 & 9.119 & 4.560 & 3.040 \\
\hline $2004^{b}$ & 4.700 & 7.048 & 1.762 & 10.573 & 5.286 & 3.524 \\
\hline $2006^{c}$ & 14.384 & 34.522 & 8.630 & 58.687 & 29.343 & 20.713 \\
\hline $2009^{c}$ & 18.790 & 45.096 & 11.274 & 76.663 & 38.332 & 27.058 \\
\hline $2011^{c}$ & 21.917 & 52.601 & 13.150 & 89.421 & 44.711 & 31.560 \\
\hline $2013^{c}$ & 63.839 & 153.214 & 38.303 & 260.463 & 130.232 & 91.928 \\
\hline $2015^{c}$ & 49.394 & 118.546 & 29.636 & 201.528 & 100.764 & 71.127 \\
\hline $2016^{c}$ & 49.024 & 117.658 & 29.414 & 200.018 & 100.009 & 70.595 \\
\hline $2017^{d}$ & 43.656 & 104.774 & 26.194 & 178.116 & 89.058 & 62.865 \\
\hline $2018^{d}$ & 42.169 & 101.206 & 25.301 & 172.050 & 86.025 & 60.723 \\
\hline
\end{tabular}

Sumber: a. ${ }^{(30)}, \mathrm{b} .{ }^{(31)} \mathrm{c}$. Perhitungan berdasarkan peta citra google earth $\mathrm{d}$. hasil penelitian

Berdasarkan produksi ikan budidaya dan jumlah pakan yang digunakan pada tahun 2016 maka jumlah beban masukkan bahan organik di perarain Waduk Jatiluhur sebesar 70.595 ton/tahun. Jika beban masukkan tersebut dibagi dengan volume maksimal perairan maka setiap liter air di Waduk Jatiluhur akan mengandung sebesar 22,1 mg/L bahan organik.

Kegiatan budidaya yang melebihi daya dukung lingkungan akan berdampak tingginya beban masukkan bahan organik ke perairan ${ }^{(32)}$. Hal ini dapat berakibat pada degradasi kualitas air ${ }^{(33)}$. Jumlah beban masukkan bahan organik di
Waduk Jatiluhur telah melebihi daya tampung yaitu sebesar $7,76 \mathrm{mg} / \mathrm{L}^{(14)}$. Pada umumnya kosentrasi bahan organik pada musim kemarau lebih tinggi jika dibandingkan dengan musim hujan sebagaimana tercantum pada Tabel 2. Hal ini berkaitan dengan penurunan beban hidrolik badan air karena pengenceran ${ }^{(14)}$.

\subsection{Laju dekomposisi bahan organik}

Laju dekomposisi (k) bahan organik di Waduk Jatiluhur berkisar $0,10-0,25$ per hari dengan BOD ultimate (Lo) berkisar 6,08-8,11 
$\mathrm{mg} / \mathrm{L}$ (Tabel 4). Sumber bahan organik di lokasi budidaya berasal dari pakan yang terbuang dan ekresi ikan. Nilai $L_{\circ}$ tertinggi selama penelitian terdapat pada lokasi Pasir Canar pada bulan Agustus sedangkan nilai $\mathrm{k}$ tertinggi terdapat di lokasi Astap pada bulan Agustus. Nila K yang diperoleh ini hampir sama dengan hasil penelitian $^{(34)}$ untuk contoh air kolam ikan yaitu 0,20-0,29 per hari. Nilai K dipengaruhi oleh komposisi bahan organik yaitu jika tersusun dari bahan organik yang tidak mudah terdegradasi laju reaksi yang rendah( ${ }^{(35)}$.

Tabel 4. BOD Ultimate $\left(L_{\circ}\right)$ dan laju peluruhan $(K)$ bahan organik di Waduk Jatiluhur

\begin{tabular}{ccccc}
\hline Lokasi & \multicolumn{2}{c}{ Februari } & \multicolumn{2}{c}{ Agustus } \\
\cline { 2 - 5 } & $\mathrm{L}_{\circ}$ & $\mathrm{K}$ & $\mathrm{L}_{\circ}$ & $\mathrm{K}$ \\
Canar $^{\mathrm{LS}}$ & 7,07 & 0,22 & 8,11 & 0,12 \\
Astap $^{\mathrm{GT}}$ & 6,10 & 0,25 & 6,21 & 0,20 \\
Pulau Aki $^{\mathrm{GT}}$ & 6,08 & 0,14 & 6,30 & 0,10 \\
\hline Catatan: subcribe huruf adalah metode & analisis data
\end{tabular}

Tingginya nilai Lo di lokasi Pasir Canar disebabkan tingginya kandungan bahan organik. Kandungan bahan organik yang tinggi pada di Pasir Canar karena lokasi tersebut dimanfaatkan sebagai lokasi budidaya ikan. Lokasi penelitian Pasir Canar juga dekat dengan muara Sungai Cilalawi yang merupakan inlet Waduk Jatiluhur. Daerah tangkapan air di Sungai Cilalawi berupa lahan pertanian dan pemukiman penduduk yang dapat menjadi sumber masukkan bahan organik. Sumber bahan organik di Waduk Jatiluhur selain berasal dari kegitan budidaya juga berasal dari luar badan $\operatorname{air}^{(36)}$

Hasil pengamatan peluruhan bahan oganik dilaboratorium dan laju peluruhan teoritis di sajikan pada Gambar 2. Nilai BOD teori secara umum berhimpit dengan nilai BOD hasil percobaan di laboratorium sehingga nilai $L_{o}$ dan $\mathrm{K}$ dapat digunakan dalam model peluruhan bahan organik orde satu.

Laju konsumsi oksigen terlarut (BOD) semakin tinggi dengan bertambahnya waktu pengamatan. Konsentrasi oksigen terlarut pada contoh air setelah aerasi berkisar 7,4-8,3 mg/L sedangkan pada akhir pengamatan adalah 1,8$2,1 \mathrm{mg} / \mathrm{L}$. Penurunan konsentrasi oksigen terlarut ini menunjukkan konsumsi oksigen terlarut selama dekomposisi bahan organik ${ }^{(37,38)}$. Laju penurunan konsentrasi oksigen persatuan waktu juga mengalami penurunan yang disebabkan oleh penurunan koonsentrasi bahan organik ${ }^{(39)}$. Hubungan antara konsentrasi bahan organik dengan Lo dapat di gambarkan dengan persamaan $Y=0,1472 x+4,8758$ dengan nilai koefisien determinasi $\left(R^{2}\right)$ 0,8368 dimana $Y=$ BOD ultimate $(\mathrm{mg} / \mathrm{L})$ dan $\mathrm{x}=$ konsentrasi bahan organik (mg/L). Persamaan tersebut menunjukkan bahwa semakin tinggi bahan organik maka nilai BOD ultimate juga akan semakin besar.

Nilai Lo dan $\mathrm{k}$ diperarian dipengaruhi oleh beban masukan bahan organik dan jumlah ketersedian oksigen terlarut diperairan ${ }^{(13)}$ dan suhu $^{(33,40,41)}$ serta $\mathrm{pH}$ perairan ${ }^{(42)}$. Nilai $\mathrm{K}$ meningkat dari 0,22 per hari pada suhu $20^{\circ} \mathrm{C}$ menjadi 0,46 per hari pada suhu $35^{\circ} \mathrm{C}^{(43)}$. Laju peluruhan bahan organik akan semakin besar dengan bertambahnya $\mathrm{pH}$ perairan sampai dengan $\mathrm{pH} 9,2^{(44)}$ dan nilai $\mathrm{K}$ bertambah i besar dari 0,0012 per hari pada kondisi anaerob menjadi 0,0029 per hari pada kondisi aerob(45). Jumlah bahan organik yang terdekomposisi pada suhu $27^{\circ} \mathrm{C}$ lebih banyak jika dibandingkan dengan suhu $20^{\circ} \mathrm{C}^{(46)}$. Nilai $\mathrm{K}$ di Waduk Jatiluhur pada musim kemarau dan hujan masing-masing adalah $0,01-0,13$ dan $0,03-0,76$ per hari(47) atau lebih kecil dari hasil penelitian ${ }^{(48)}$ yaitu sebesar 0,13-0,28 per hari. Hal ini disebabkan oleh jumlah KJA yang beroperasi lebih tinggi pada tahun 2013 (63.839 petak) jika dibandingkan dengan tahun 2003 (2882 petak) dan 2016. Nilai $\mathrm{k}$ bahan organik di Waduk Jatiluhur lebih kecil dari cairan lindi berkisar 0,242-0,331 per hari(4). Laju dekomposisi bahan organik diperairan dipengaruhi oleh suhu dan jenis dari bahan organik $(49,50,51)$.

Dekomposisi 1 molekul bahan organik $\left(\mathrm{C}_{6} \mathrm{H}_{12} \mathrm{O}_{6}\right)$ memerlukan 6 molekul oksigen terlarut $\left(\mathrm{O}_{2}\right)$ yang akan menghasilkan 6 molekul air $\left(\mathrm{H}_{2} \mathrm{O}\right)$ dan 6 molekul karbondioksida $\left(\mathrm{CO}_{2}\right)^{(24)}$. Kandungan bahan organik berdasarkan beban cemar dengan volume waduk sebesar $2,97 \times 10^{12}$ L berkisar 0,37-30,95 mg/L. Dekomposisi bahan organik akan berhenti pada hari ke 45 (beban tahun 1998) sampai dengan hari ke 90 (beban tahun 2013) (Gambar 3). Berdasarkan reaksi dekomposisi bahan organik, hal ini dapat terjadi jika oksigen terlarut tersedia sebanyak 6 kali lebih besar dari kandungan bahan organik di perairan yang berasal dari kegiatan budidaya.

Berdasarkan kandungan oksigen terlarut jenuh yaitu 7,7-8,01 mg/L (Tabel 2) maka bahan organik mampu didekomposisi hanya sebesar 1,3-1,4 mg/L. Beban bahan organik pada tahun 1998-2004 akan terdekomposisi seluruhnya sedangkan pada beban bahan organik pada tahun 2005-2018 akan terdekomposisi sebesar $6,5 \%$ dari beban bahan organik. Akumulasi bahan organik diperairan hingga akhir 2018 diperkirakan sebesar $4,81 \mathrm{~kg} / \mathrm{m}^{2}$ atau 404.100 ton. Dekomposisi bahan organik berdasarkan beban cemar tahun 2006-2018 akan berhenti pada hari ke 4 karena ketersediaan oksigen terlarut diperairan telah habis $(0 \mathrm{mg} / \mathrm{L})$. Akumulasi bahan organik juga terjadi karena Waduk Jatiluhur menerima beban bahan organik dari luar badan air(36). 

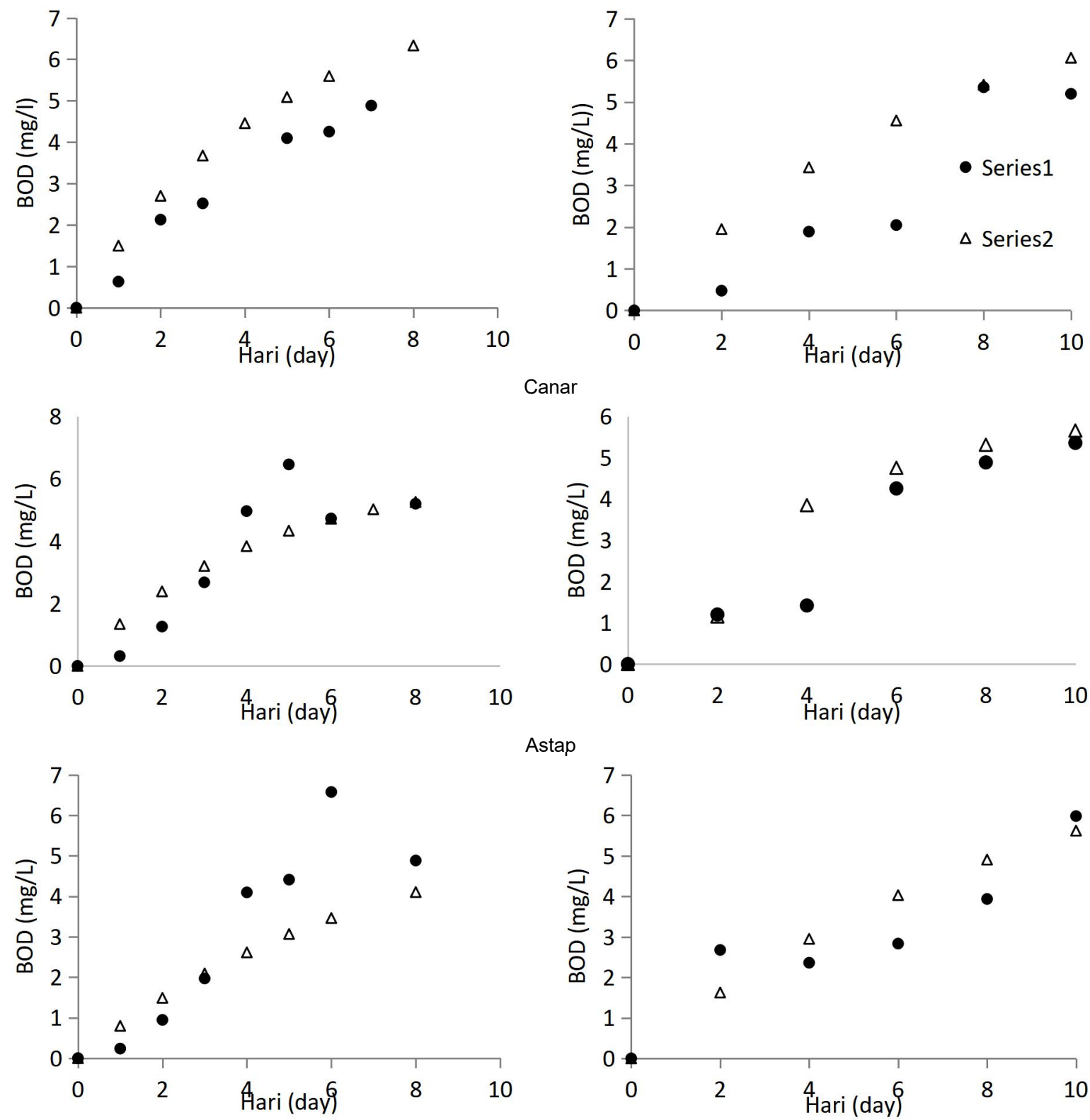

Astap

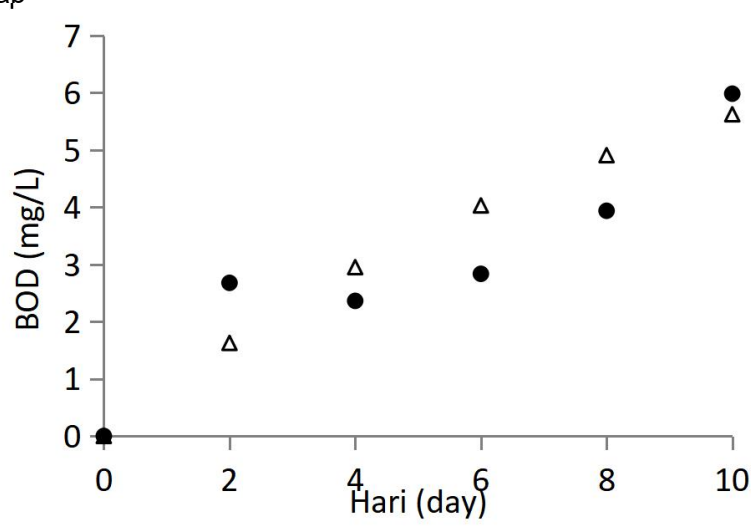

Pulau Aki

Gambar 2. Nilai BOD di Waduk Jatiluhur A. Februari B. Agustus

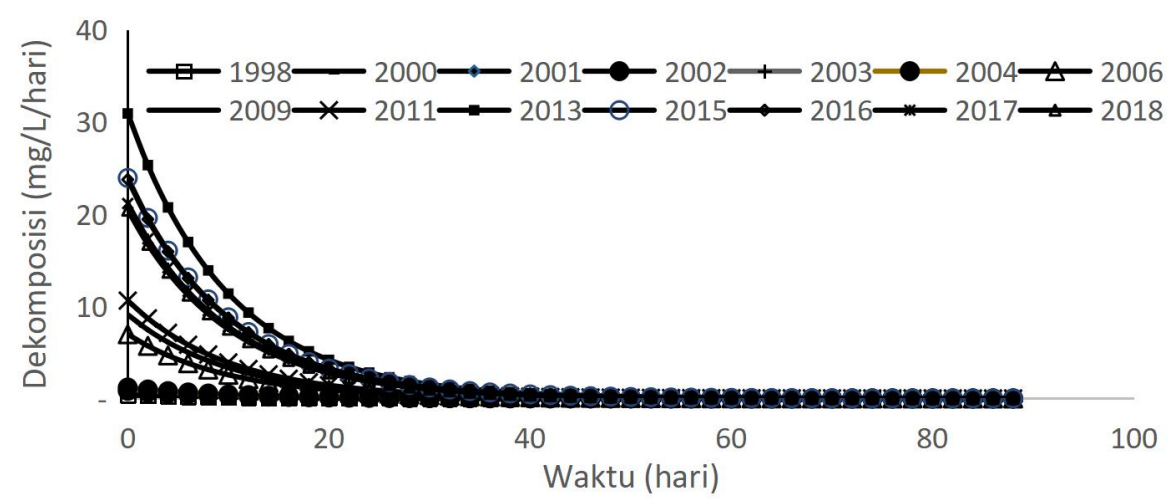

Gambar 3. Simulasi dekomposisi bahan organik di Waduk Jatiluhur 


\section{KESIMPULAN}

Beban masukkan bahan organik dari kegiatan budidaya di Waduk Jatiluhur sebesar 70.595 ton/tahun atau $22,1 \mathrm{mg} / \mathrm{L}$ dan telah melebihi daya tampung perairan. Nilai $L_{o}$ berkisar 6,8-8,11 mg/L dengan nilai $\mathrm{k}$ berkisar $0,10-.0,25$ per hari. Beban masukkan bahan organik ini berakibat penurunan konsentrasi oksigen terlarut. Nilai $L_{o}$ di Waduk Jatiluhur dipengaruhi oleh konsentrasi bahan organik.

\section{PERSANTUNAN}

Tulisan ini merupakan bagian dari penelitian "Pemulihan Populasi Ikan dan Rehabilitasi Lingkungan di Waduk Ir. $H$. Djuanda, Purwakarta" Balai Riset Pemulihan Sumberdaya Ikan Tahun Anggaran 2017. Penulis mengucapkan terima kasih kepada Ir. Amran Ronny Syam, M.Si atas saran untuk perbaikan tulisan ini.

\section{DAFTAR PUSTAKA}

1. Shmeis, R. M. A. (2018). Water chemistry and microbiology. In Comprehensive Analytical Chemistry: Elsevier: 1-56

2. Xinglong, J \& Boyd, B. E. (2005). Measurement of 5-day biochemical oxygen demand without sample dilution or bacterial and nutrient enhancement. Aquaculture Engineering 33: 250-257

3. Siwiec, T., Kiedrynska, L., Abramowicz, K \& Rewicka, A. (2012). Analysis of chosen models describing the change in $\mathrm{BOD}_{5}$ in sewage. Environment Protection Engineering 38(2): $61-76$

4. Cecen, F \& Yangin, C. (2001). Application of various $B O D$ test methods in landfill leachates. J. Environ. Sci. Health A36(4), 545-564.

5. Marske, D. M \& Polkowski, L. B. (1972). Evaluation of methods for estimating biochemical oxygen demand parameters. Journal Water Pollution Control Federation 44(10): 1987-2000

6. Kale, V. S. (2016). Consequence of temperature, $\mathrm{pH}$, turbidity and dissolved oxygen water quality parameters. International Advanced Research Journal in Science, Engineering and Technology 3(8): 186-190

7. Sullivan, A. B., Snyder, D. M \& Rounds, S. A. (2010). Controls on biochemical oxygen demand in the upper Klamath River, Oregon. Chemical Geology 269: 12-21

8. Al-Sulaiman, A. M \& Khudair, B. H. (2018). Correlation between $\mathrm{BOD}_{5}$ and $\mathrm{COD}$ for Al-
Diwaniyah wastewater treatment plants to obtain the biodigrability indices. Pak. J. Biotechnol 15(2): 423-427

9. Gonzalez-Silvera, D., Izquierdo-Gomez, D., Fernandez-Gonzales, V., Martinez-Lopez, F. J., Lopez-Jimenez, J. A. \& Sanches-Jerez, P. (2015). Mediterranean fouling communities assimilate the organic matter derived from coastal fish farms as a new trophic resource. Marine Pollution Bulletin 91(1): 45-53

10. Dos Santos Rosa, R., Aguiar, A. C. F., Boechat, I. G \& Gucker, B. (2013). Impact of fish farm pollution on ecosystem structure and function of tropical headwater streams. Environmental Pollution 174: 204-213

11. Neumeier, U., Friend, P. L., Gangelhof, U., Lunding, J., Lundkvist, M., Bergamasco, A., Amos, C. L \& Flindt, M. (2007). The influence of fish pellets on the stability of seabaed sediment: A laboratory flume investigation. Estuary, Coastal and Shelf Science 75: 347357

12. Widyastuti, E., Sukanto \& Setyaningrum, N. (2015). Pengaruh limbah organik terhadap status tropik, rasio N/P serta kelimpahan fitoplankton di Waduk Panglima Besar Soedirman Kabupaten Banjarnegara. Biosfera 32(1): 35-41

13. Astuti, L. P., Adiwilaga, E. M., Setiawan, B. I \& Pratiwi, N. T. M. (2014). Effect of aeration on the rate of biochemical oxygen demand (BOD) in floating net cages in Ir. H. Djuanda Reservoir, West Java, Indonesia. Journal of Applied Biotechnology 2(2): 82-90

14. Simarmata, A. H., Adiwilaga, E. M., Lay, B. W \& Prartono, T. (2008). Kajian keterkaitan antara cadangan oksigen dengan beban bahan organik di Zona Lakustrin dan Transisi di Waduk Ir. H. Djuanda. J. Lit. Perikan. Ind. 14(1): 1-14

15. Salmin. (2005). Oksigen terlarut (DO) dan kebutuhan oksigen bilogi (BOD) sebagai salah satu indikator untuk menentukan kualitas perarain. Oseana XXX (3): 21-26

16. Krevs, A., Kucinskiene, A. (2012). Microbial decomposition of organic matter in the bottom sediments of small lakes of the Urban Landscape (Lithuania). Microbial 81(4): 477483

17. APHA (American Public Health Association). (2005). Standard Methods for the Examination of Water and Waste Water Including Bottom Sediment and Sludges. $21^{\text {st }}$ edition. In: Eaton $A D$, Clesceri LS, Rice EW, Grennberg AE. Amer. Publ. Health Association Inc. New York $1296 p$ 
18. Yun-Young, C., Seung-Ryong, B., Jae-In, K., Jeong-Woo, C., Jin, H., Tae-U, L., Cheol-Joon, $P$ \& Lee, B. J. (2017). Characteristics and biodegradability of wastewater organic matter in municipal wastewater treatment plant colleting domestic wastewater and industrial discharge. Water 9(409): 1-12

19. Ammary, B. Y. \& Al-Samrraie, L. A. (2014). Evaluation and comparison of methods used for the determination of BOD first-order model coefficient. Int. J. Environment and Waste Management 13(4): 362-375

20. Palys, T. (2008). Purposive sampling. In Given, L. M (Edt). The Sage Encyclopediaof Qualitative Research Methods 2 Sage. Los Angeles, 697-698

21. Garno, Y.S. (2002). Beban pencemaran limbah perikanan budiaya dan yutrofikasi di perairan waduk pada DAS Citarum. Jurnal Teknologi Lingkungan 3(2): 112-120

22. Junaidi., Syandri, H. \& Azrita. (2014). Loading and distribution of organic materials in Maninjau Lake West Sumatra ProvinceIndonesia. J. Aquac. Res. Development 5(7): $1-4$

23. Schmittou, H. R. (1991). Budidaya Kermba: Suatu metode produksi ikan di Indonesia. FRDP, Puslitbang Perikanan, Jakarta. 126

24.JI, G. Z. (2008). Hydrodynamics and water quality: modelling river, lakes, and estuaries. Jhon Wiley \& Sons. Canada. 676p

25. Singh B. (2004). Determination of BOD kinetic parameters and evaluation of alternate methods. Thesis. Department of Biotechnology \& Environmental Sciences. Thapar Institute of Engineering \& Technology. p 74

26. Oke, I. A \& Akindahunsi, A. A. (2005). A statistical evaluation of methods of determining BOD rate. Journal of Applied Science Research 1(2): 223-227

27.Siwiec, T., Kiedrynska, L., Abramowicz, K., Rewicka, A. \& Nowak. P. (2011). BOD measuring and modelling methods - review. Ann. Warsaw Univ. of Life Sci. - SGGW Land Reclam. 43 (2): 143-153

28. Sibil, R., Berkun, M \& Bekiroglu, S. (2014). The comparison of different mathematical methods to determine the BOD parameters, a new developed methods and impacts of these parameters on the design of WWTPs. Applied Mathematical and Modelling 38: 641-658

29. Possignolo, N.V., Bertoncini, E.I., Vitti, A. C. (2017). Decomposition of the organic matter of natural and concentrated vinasse in sandy and clayey soils. Water science and Tecnology 76(3):728-738

30. Abery, N. W., Sukadi, F., Budhiman, A. A., Kartamihardja, E. S., Koeshendrajana, S., Buddhiman., De Silva. (2005). Fisheries and cage culture of three reservoirs in west java, Indonesia, a case study of ambitious development and resulting interactions. Fisheries Management and Ecology 12: 31533031

31. Astuti, L.P. (2015). Intervensi internal terhadap biodegradasi bahan organik limbah keramba jaring apung di Waduk Ir. $\mathrm{H}$. Djuanda dalam upaya memperbaiki kualitas perairan. Disertasi. Sekolah Pasca Sarjana Institut Pertanian Bogor. 52p

32. Garno, Y. S. (2006). Contribution of the organic waste from fish culture on the degradation of the water quality of reservoir Cirata. J. Tek. Ling 7(3): 302-310

33. Henny, C \& Nomosatryo, S. (2016). Changes in water quality and trophic status associated with cage aquaculture in Lake Maninjau, Indonesia. IOP Conf. Series: Earth and Environmental Science 31:1-9

34. Mason, I. G., McLachlan, R. I \& Gerard, D. T. (2006). A double exponential model for biochemical oxygen demand. Bioresource Technology 97: 273-282

35. Maiti, M., Majumder, S \& Santra C. (2018). A comparative study of BOD rate constanta of two waste water samples. International Journal of Engineering Technology Science and Research 5(1):1219-1222

36. Tjahjo, D.W.H \& Purnamaningtyas, S.E. (2008). Kajian kualitas air dalam evaluasi pengembangan perikanan di Waduk Ir. $\mathrm{H}$. Djuanda, Jawa Barat. J. Lit. Perikan. Ind. 14(1): $15-30$

37. Erses, A. S., Onay, T. T \& Yenigun, O. (2008). Coparison of aerobic and anaerobic degradation of municipal solid waste in bioreactor landfills. Bioresource Tecnology 99: 5418-5426

38. Scow, K. M \& Alexander, M. (1992). Effect of diffusion on the kinetics of biodegradation: experimental result with synthetic aggregates. Soil Sci. Soc. Am. J. 56: 128-1343

39. Vahatalo, A. V., Aarnos, H \& Mantyniemi. (2010). Biodegradability continuum and biodegradation kinetics of natural organic matter described by the beta distribution. Biogeochemistry 100: 227-240

40. Conant, R. T., Ryan, M. G., Agren, G. I., Birge H. E., Davidson, E. A., Eliasson, P. E. (2011). 
Temperature and soil organic matter decomposition rates-synthesis of current knowlwdgw and a way forward. Global Change Biology 17: 3392-3404

41. Kirwan, M. I., Guntensperger, G. R., Langley, J. A. (2014). Temperature sensitivity of organic-matter decay in tidal marshes. Biogeosciences 11: 4801-4808

42. Kelly, C. A., Rudd, J. W. M., Furutani, A. \& Schindler, D. W. (1984). Effect of lake acidification on rates of organic matter decomposition in sediments. Linmol. Oceanogr. 29(4): 687-694

43. Chaudhuri, N., Tyagi, P. C., Niyogi, N., Thergaonkar, V. P., Khanna, P. (1992). BOD test for tropical countries. J. Environ. Eng 118: 298-303

44. Krachler, R. F., Krachler, R., Stojanovic, A. Wielander, B. \& Herzig, A. (2009). Effect of $\mathrm{pH}$ on Aquatic biodegradation processes. Biogeosciences Discuss 6: 491-514

45. Bianchini Junior, I., Cunha-Santino, M. B., Ribeiro, J. U., Penteado, DGB. (2014). Implicatiom of anaerobic and aerobic of Eichhornia azurea (Sw.) Kunth. On the carbon cycling in a subtropical reservoir. Braz. J. Biol 74(1): 100-110

46. Dhage, S. S., Dalvi, A. A. \& Prabhu, D. V. (2012). Reaction kinetics and validity of BOD test for domestic wastewater released in marine ecosystems. Environ. Monit. Assess. 184: $5301-5310$

47. Simarmata, A. H. (2007). Kajian keterkaitan antara kemantapan cadangan oksigen dengan baban masukkan bahan organik di Waduk. Ir. H. Djuanda Purwakarta, Jawa Barat. Disertasi. Sekolah Pasca Sarjana. Institut Pertanian Bogor. Bogor. 142p

48. Astuti, P. L \& Pratiwi, N. T. M. (2016). Evaluasi metode penentuan parameter biochemical oxygen demand (BOD). Limnotek 23(1): $44-49$

49. Attiogbe, F. K., Glover-Amengor, M \& Nyadziehe, K. T. (2007). Correlating biochemical and chemical oxygen demand of effluents- A case study of selected industries in Kumasi, Ghana. West African Journal of Applied Ecology 11: 155-164

50. Hoffmann, B., Muller, T \& Jorgensen, G. (2010). Carbon dioxide production and oxygen consumption during the early decomposition of different litter types over a range of temperatures in soil-inoculated quartz sand. Plant Nutr. Soil Sci 173: 217-223

51.Dolgonosov, B. M., Gubernatorova, T. N. (2010). Modelling the biodegradation of Multicomponent organik matter in an aquatic environment: 1. Methodology. Water Resourcess 37(3): 311-319 